\title{
Female facing dual burden of malnutrition : A brief study of Bhagalpur
}

\author{
VIMI SINGH AND MAMTA KUMARI
}

Received: 26.03.2015; Accepted: 24.05.2015

See end of the paper for authors' affiliations

\section{VIMI SINGH}

Department of Home Science, S.M. College (T.M.B.U.) BHAGALPUR (BIHAR) INDIA Email : vimiachal28@gmail.com
DABSTRACT : Currently, the city is undergoing rapid socio-economic demographic nutritional and health transition. Although Bhagalpur has not yet overcome the problems of poverty, under nutrition and communicable diseases, it is increasingly facing additional challenges related to diseases of over-nutrition that results from urbanization and economic betterment. The purpose of the study was to describe, - the nutrition transition in Bhagalpur in term of double burden of malnutrition; - to create a better picture of both extremes under nutrition (Anaemia_ and over nutrition (related disease). Methodology : This paper conducted a study on 200 women of age belonging to 20 to 50 years because this is more venerable age. 100 women of age belonging to 20 to 50 years because this is more venerable age. 100 women from each groups were selected. To know the impact of under nutrition blood hemoglobin level was tested and assessed on who scale, for the second case to study height and weight was assessed. Result : The study finds that 51 per cent and 21 per cent in age of 20 to 30 years 25 per cent and 21 per cent and 21 per cent were in age of 30 to 40 years and 24 per cent and 35 per cent in age of 40 to 50 years was found in the case of under nutrition and over nutrition, respectively. According to WHO threshold, it was found, 25 per cent case of moderate, 16.16 per cent severe 10 per cent border line and 9 per cent less than $6 \mathrm{Hb} / \mathrm{g} / \mathrm{Dl}$. (Total $60 \%$ Anemic). It was remarkable to see that only 40 per cent cases were normal. On the other half of the study we found that 44 per cent women were overweight, / Obesity. Conclusion : This study found that the town is now facing dual burden of malnutrition that clearly draw a picture of health transition.

KEY WORDS: Dual burden, Obesity, Anemia, Women health

- HOW TO CITE THIS PAPER : Singh, Vimi and Kumari, Mamta (2015). Female facing dual burden of malnutrition : A brief study of Bhagalpur. Asian J. Home Sci., 10 (1) : 254-259. 